\title{
Lessons in Creativity from the Innovative Design of the Swatch
}

\author{
Gilles Garel
}

\author{
"I see no advantage in these new clocks. They run no faster") \\ than the ones made 100 years ago.
}

Henry Ford (1863-1947)

Business magnate and founder of Ford Motor

\begin{abstract}
No space is off-limits to innovation, even those occupied for many years by leading players and proven solutions. The case of the innovative Swatch watch, re-examined in this article with new information and insights, demonstrates that, without knowledge, design is not possible; but, with only knowledge, all we can do is reproduce. Innovation also requires creativity, the introduction of new concepts. Knowledge needs to be associated with unbridled, surprising, and hitherto unknown creativity, as described by the concept-knowledge theory of design. In this article, a new analysis of the well-known but misunderstood case of the Swatch yield lessons about the importance of creativity and knowledge in developing innovative products.
\end{abstract}

\section{Introduction}

If all rival companies had the need to innovate on a permanent basis, many would be wary because innovation always represents risk. This risk is not only financial but also somewhat philosophical, because it requires acceptance of uncertainty, the possibility that the result does not correspond to what was initially planned, and the potential for complete failure. Faced with these fears, renovation often prevails over innovation: everyone dreams of revolution but most firms end up working towards evolution. It is "starkly rational", explains Christensen (1997).

Strategic management research can explain the actions of leaders through mimicry, but without clear points of reference. When it is foggy, and you have no clue of where to go, you follow the person right in front of you, because it is reassuring to have someone to lead the way. But does that necessarily mean that you are on the right path? When everyone follows everyone else, we all go round in circles. Fortunately, the innovator is there to break that circle. The innovator refuses to accept the situation as it is. The innovator breaks the rules, moves to the side, shifts everything around, goes beyond the framework in order to challenge and set a new one. The innovator chooses the side roads and takes the risk of starting a revolution.

How do you go about changing how you think in such a way that you end up creating new ideas that were previously considered impossible or unacceptable? This article starts with this broad question and uses it to revisit the case of the Swatch watch. The aims of this article are to unveil the unknown story of the Swatch design to highlight the innovation mechanisms that took place and to extract lessons to apply to other innovation contexts. The Swatch design process is analyzed through to the concept-knowledge theory of design. Throughout the Swatch design story, there was continuous interaction between concepts and knowledge, with engineers participating in conceptual matters and with creative people involved in engineering matters. Without knowledge we cannot design; but with only knowledge, we only reproduce. Innovation requires knowledge and creativity. On the other hand, the Swatch case highlights how designers both eliminated and reused various components.

Technology innovation never starts from scratch. Thus, we first revisit the history of the watch industry in Switzerland and the industrial crisis that the industry 


\section{Lessons in Creativity from the Innovative Design of the Swatch}

\section{Gilles Garel}

faced in the late 1970s. Then, we examine the development of the Swatch as innovation in response to this crisis. Then, by analyzing the interactions between concepts and knowledge through the interactions between engineers and designers, we are able to extract valuable lessons about creativity in innovation.

\section{The Swatch Design: The Unknown Story}

"Every business person knows the Swatch story" (Moon, 2004). The "Swatch" is a quartz wrist watch, made of welded plastic. It is simple-looking, sturdy, very inexpensive to manufacture, and it possesses the quality and durability of traditional Swiss watches. This watch is also known for its drawings, designs, and infinite colours that have been created over many years and through multiple re-launched collections. It is more than a functional object. It is a creative, artistic, emotional, and fashion accessory. On March 1, 1983, the first Swatch watch was launched on the Swiss market. Today, Swatch is among the iconic brands of the world. Nearly 550 million Swatch watches, of various models, have been sold. Before Swatch, it seemed impossible to mass produce and sell a quality Swiss watch for barely 50 Swiss francs while achieving comfortable margins. More than thirty years later, the watch remains virtually unchanged from its original version - an exceptional accomplishment for a consumer product. The history of Swatch is so well known that it seems vain to revisit it.

But actually, the genesis of the Swatch flagship innovation is actually unknown or falsely known. This distorts the lessons that one can normally draw from such an innovation. Until now, we have known little about the pre-launch period, the time that elapsed between the original concept of the Swatch and its early success on the market. Yet, this period is rich for learning about innovation and creativity management. Many studies concerning the Swatch have already been conducted (Gabarro \& Zehnder, 1994; Tushman \& Radov, 2000). These publications are characterized by two main ideas. First, they begin at the point of the initial product launch on the consumer market and largely neglect the pre-launch conceptualization and development of the product, thus focusing on Swatch as a marketing success; much attention is given to the global distribution, permanent recovery design, and affordable fashion accessories associated with the product. Secondly, the approach of these studies promotes the notion of an inspired vision of a great leader. An individual imagines a future innovation and their vision is turned into reality by engineers and skilled marketers. Such an analysis could be inspiring and flattering for future senior managers who can imagine how they would be able to influence the course of business life by their personal inventiveness. However, this interpretation of the history of Swatch is not borne out by a thorough analysis of the facts. Contrary to popular belief, the famous Swatch watch was not invented by Nicolas Hayek (Wegelin, 2009), who arrived at the company two years after the original concept was devised. The paternity and managerial mythology is still an interesting question when you deal with innovation and creativity management.

Very few people who have written about the Swatch management were close to the real actors, the people who actually created the design. We only had access to some of the firm's archives, because the Swatch Group did not support our efforts. Now, we have been able to interview actors involved in producing the Swatch, in addition to consulting academic works, including case studies and articles in the business press and Swiss newspapers published around the time the Swatch was launched. In particular, this article draws upon on $L a$ fabrique de l'innovation (Garel and Mock, 2012), a book written by the current author (a researcher) and Elmar Mock, one of the two inventors of the Swatch. Indeed, we found that the pre-launch period in the Swatch story is rich for learning about innovation and creativity management. How was the Swatch invented? Where did the original concept come from? What are the innovative management principles that can be learned from this design?

The search for answers to these questions must be undertaken with an understanding of the historical context of the Swiss watch industry. In 1980, the cheapest watch movements cost 14 Swiss francs. The cost of producing a complete watch with hands, case, bracelet, packaging, and warranty cards was 25 Swiss francs. However, economic realities within the industry led Ernst Thomke, the CEO of ETA (today part of Swatch group), to mandate a production cost of 10 francs. To achieve a radical $60 \%$ cost reduction, one thing was clear: there must be no reliance on past experience to achieve the required improvements. All previous knowledge and experience must be challenged. Instead of looking to the past and searching for improvements, they would have to start from scratch and design a completely new watch. The Swatch was developed in a time of crisis, which both shaped and stimulated the innovation. 


\section{Lessons in Creativity from the Innovative Design of the Swatch}

\section{Gilles Garel}

\section{A Deep Industrial Crisis}

In the late 1970s, a crisis directly threatened the survival of the Swiss watch industry. After World War II, Switzerland controlled $90 \%$ of timepiece production and retained, until $1970,85 \%$ of the world wristwatch market. In just ten years, its share of the market collapsed; by 1980 , it controlled only $22 \%$ of the market. In 1983, this share dropped even further to $15 \%$ (Donzé, 2009). Asian competitors, mainly Japanese, started pushing the Swiss out, notably by offering cheap quartz watches. The Swiss had invented quartz technology, liquid crystal displays, and the first electronic watches, but it was in Asia that these technologies were transformed into new products at the end of the 1970s. These countries flooded world markets with digital and analog quartz wristwatches, which even replaced cheap, but less accurate, Swiss mechanical watches such as the Roskopf. At that point, anyone could make an accurate timepiece without skills in the art of watchmaking. This new reality represented an upheaval, a major paradigm shift in the sector: accuracy no longer depended on quality work and therefore price. The wristwatch was now available to all and the Swiss were the big losers in this revolution. Any company could now buy very low-cost quartz movements and enter the world wristwatch market. The crisis had catastrophic consequences in terms of employment. Between 1970 and 1980, the Swiss watchmaking industry lost twothirds of its workforce, shifting from 90,000 employees to around 30,000 . Of the 300 million watches sold worldwide at the start of the 1970s, only 80 million were produced in Switzerland. Quartz replaced mechanical movements, transforming the Swiss industry into a museum for luxury brands. At the start of the 1980s, Switzerland was completely absent from a world market of 450 million watches for less than $\$ 100$, while it represented $97 \%$ of the market for watches with price tags over $\$ 350$. Foreign competitors even offered to buy up prestigious brands such as Omega, Longines, and Tissot. In 1980, the Swiss watch industry was indeed threatened with extinction.

\section{Innovation in Response to a Crisis: The Swatch Project}

The saga of the Swatch started at the end of 1979 at ETA, a key firm in the Swiss watchmaking cartel industry. The initiative was triggered by an unlikely encounter involving three people from ETA: one senior manager, Ernst Thomke (the CEO), and two young Swiss-French engineers at the bottom of the corporate ladder, Elmar Mock and Jacques Müller. The Swatch was never planned. It was not the result of a deliberate innovation strategy, a carefully thought out scheme or a brilliant vision.

The first Swatch drawing (Figure 1), which at this time was named "Vulgaris", was proposed to Thomke by Mock and Müller on March 27, 1980. Even though it looked like a child's drawing, Ernst Thomke decided to support the engineers who had represented what they

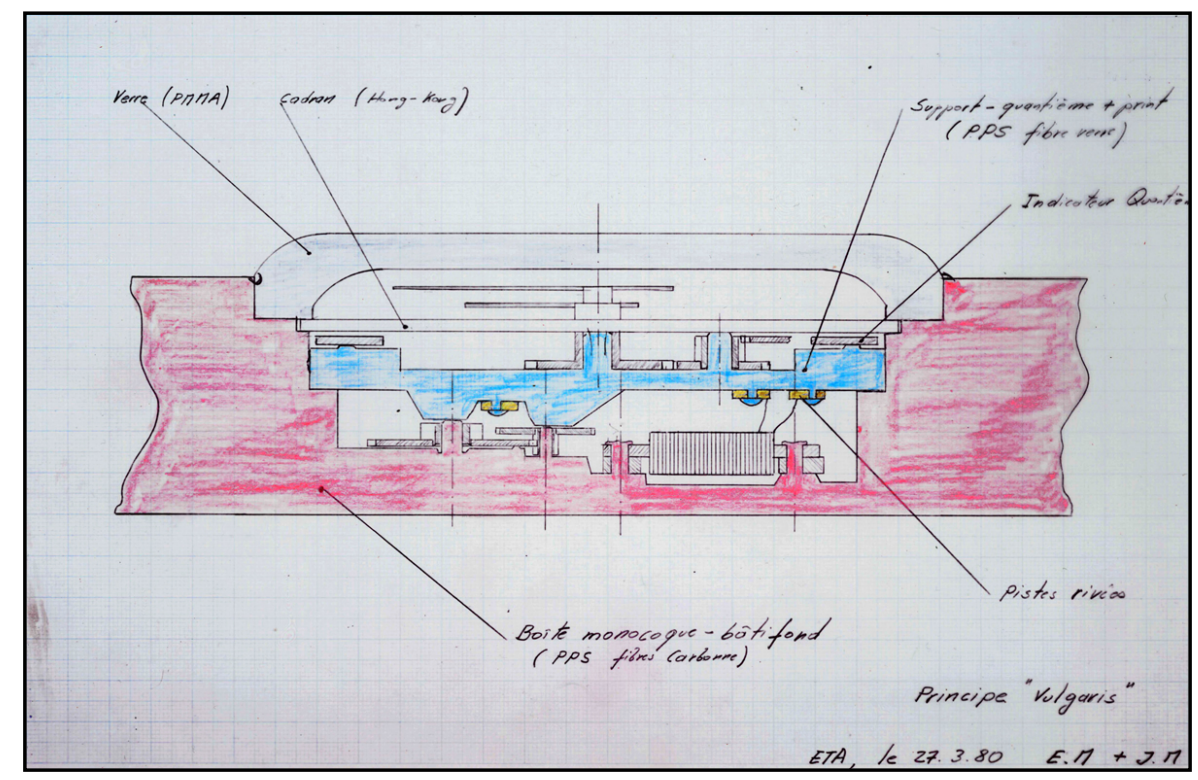

Figure 1. First sketch of the "Vulgaris" watch (March 27, 1980), which ultimately became the Swatch. Reproduced with permission of Elmar Mock. 


\section{Lessons in Creativity from the Innovative Design of the Swatch}

\section{Gilles Garel}

envisioned from their own experiments with a new engineering plastic process. Thomke had already requested his $R \& D$ group to design a radically different watch, but he had received no worthy proposals. Mock and Müller's design was the first concrete and tangible proposal. There is no innovation without a definitive representation that speaks to the decision maker: a drawing, a model, a prototype, etc. Mock and Müller's simple drawing and proposed process clearly spoke the decision maker: the project was launched and would finally be completed in exactly three years with the launch of the Swatch onto the European market on March 1st, 1983 (Figure 2).

However, the European launch was not the first. In November 1982, the Swatch experienced an early setback with a failed launch of 10,000 watches in Houston Texas. Marvin Traub, CEO of Bloomingdale's, did not want to promote and sell such a product. He demanded at least twenty different models, a new collection every six months, and not only colourful watches, but designer watches as well. The American launch, while a commercial failure, was a decisive learning experience in differentiating the watch. The American market was in fact a test of ETA's iterative process of designing the Swatch: work well and fast, act without delay, learn, and try again.

\section{Innovation as a Rigorous and Continuous Interaction between Concepts and Knowledge}

To return to the pre-launch activities, the story of Swatch actually started on the plastic-process side. Because Mock learned how car signal lights and headlamps were welded, he was able to experiment with, and then propose, solutions for, mounting plastic glass onto the plastic case of an injection-molded watch. After his training, he met with many plastic suppliers, and in particular with Branson, a manufacturer of plastic-welding machines, who would lend him equipment. Mock was also influenced by compass designs, certain of which are assembled using ultrasonic welding and contained liquids. After many trials and discussions, the technological choice of ultrasound welding prevailed. ETA would gradually acquire new knowledge in plastics and, above all, learn how to use them. The choice of ultrasound entails paradoxical consequences: a strong and water-resistant watch, a low-cost product (that would also contribute to achieving one of the criteria of a 10 Swiss Franc production cost), and an "unrepairable watch", which constitutes a very innovative but perplexing property. Why bother to repair a product that only cost 5 francs to manufacture? And, because the watch is welded, it cannot be repaired, and because it cannot be repaired, its manufacturing pro-

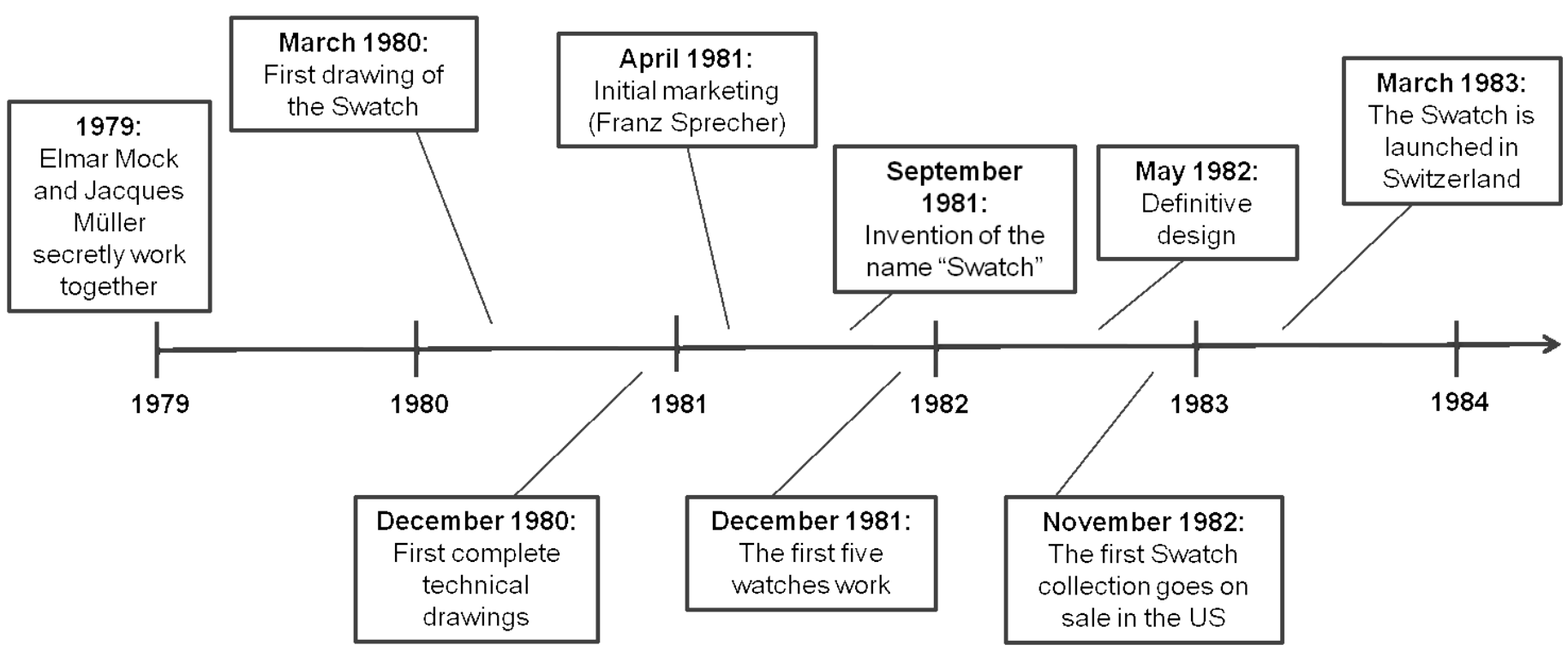

Upstream

Development

Figure 2. The Swatch timeline 


\section{Lessons in Creativity from the Innovative Design of the Swatch}

\section{Gilles Garel}

cess must be flawless. Although the impossibility of repairing the Swatch could have put the brakes on the project, in the end, this characteristic forced the firm to constantly improve its mastery of the manufacturing process. This constraint condemned the firm to strive for total quality, which spurred on the designers to increase the performance of the process and quality of the watch. Finally, the quality of the Swatch was based on a simplified architecture and reduced number of components to 51, down from the more than 150 parts required to make a traditional mechanical watch and even less than the 91 parts needed to make a quartz model. The design cycle is a virtuous one: a welded watch $\rightarrow$ that cannot be repaired $\rightarrow$ produced with zero defects $\rightarrow$ running without fail $\rightarrow$ built using a simplified architecture $\rightarrow$ with a reduced manufacturing cost $\rightarrow$ and a reliable process.

The design process was not spawned by an initial product brief, but exploited new industrial knowledge to define innovative concepts. According to the concept-knowledge theory (Hatchuel \& Weil, 2002, 2003; Le Masson et al., 2010), the design process therefore consists of an interaction between a concept space (including ideas considered outrageous: in the concept space reside propositions that are neither true nor false), which gradually takes shape, and the knowledge space (in the knowledge space reside propositions with known logical status: we know whether they are true or false), which develop concomitantly. The cycle progresses with a back-and-forth movement. A concept is created and challenged, from which knowledge is pro- duced, which is then used to challenge and create a new concept. In other words, the concept highlights insufficiencies in the knowledge of the different players who explore them and trigger the development of new knowledge that, in return, calls into question the concept, which can then be extended to new partitions or innovative proposals, as depicted in Figure 3.

Further innovation and iteration occurred when Franz Sprecher, consultant and former relation of Thomke, became the lead marketing for the Swatch design. He arrived after main architecture has been frozen by the engineers, but together, Sprecher and Thomke would transform the watch into an interchangeable accessory, a bit like a tie or earrings. The Swatch was "fashion that ticks", according to Sprecher. This fundamental turning point would transform the technical object into an innovation as a fashion product. Sprecher enriched the original concept of the Swatch as a low-cost, Swissmade watch, by shifting and extending it and positioning himself as a visionary strategist behind a world watch and accessory for the masses. This was no ersatz product - it was not a fake, low-cost Rolex in plastic, for example - but a full-fledged innovation.

Sprecher also considered the product as a perpetual event, with a continuously renewed lifecycle via the repeated launch of new Swatches into the market. At that time, the lifecycle of a product was defined in terms of duration, not as the continuous redefinition of the product itself, and thus Sprecher's approach to the product lifecycle was a further innovation.

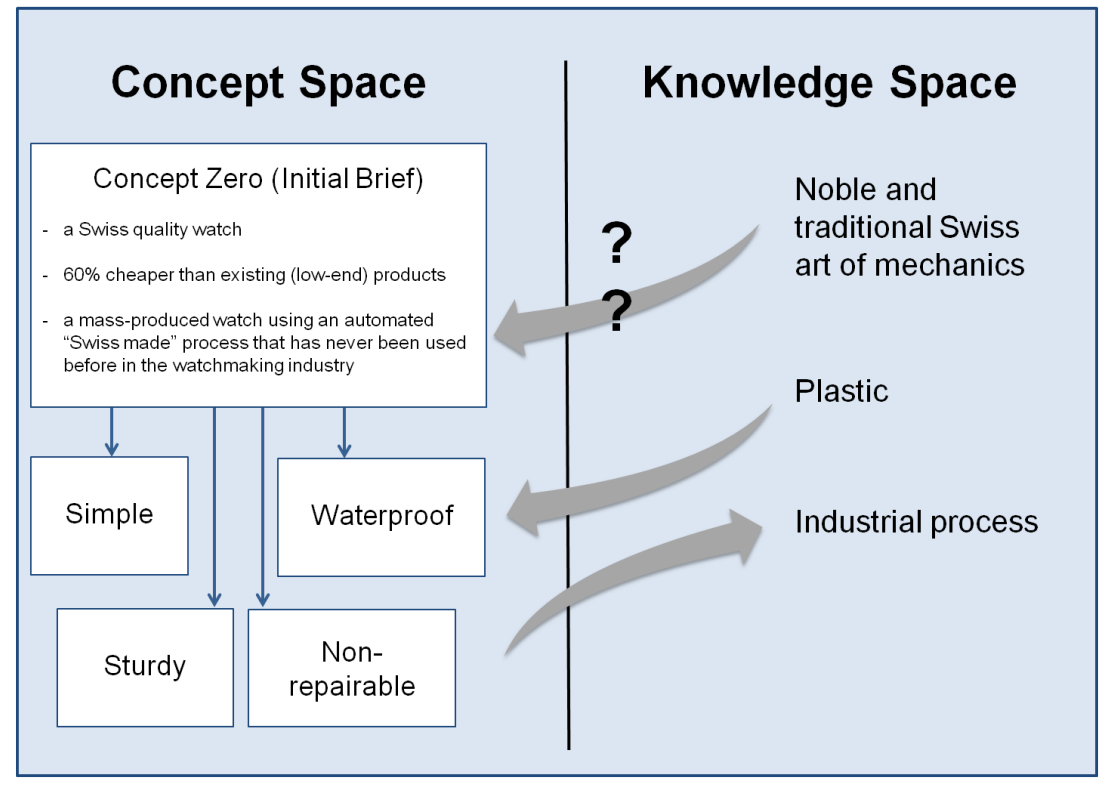

Figure 3. Interactions between concept and knowledge spaces in the early stages of the Swatch design 


\section{Lessons in Creativity from the Innovative Design of the Swatch}

\section{Gilles Garel}

The fashion orientation put forward by Sprecher influenced the external shape of the Swatch. The designers could not imitate metal cases that were the reference at that time. Fake metal was trendy then, but it was also a trap that needed to be avoided. The challenge was to make something "noble" out of plastic. To achieve this goal, the designers proposed case shapes that were neutral: like water, they were colourless, tasteless, and insipid. The Swatch design would stand out by its lack of character. The watch was to be subdued. The simplicity and neutrality of its design would not shock anyone. The case, with its lack of charisma and boldness, was meant to blend in and be accepted. This was the beauty of its design. The excellent neutrality of the shape would allow the watch to work with all sorts of graphic designs. The plastic's tactile qualities (a softtouch matte plastic) result from sanding the mold that shapes the polymer resin. The Swatch must be seamless, without any rough edges. To achieve such a result, engineers and designers had to closely work together through the concept-knowledge iterations described earlier and illustrated in Figure 4.

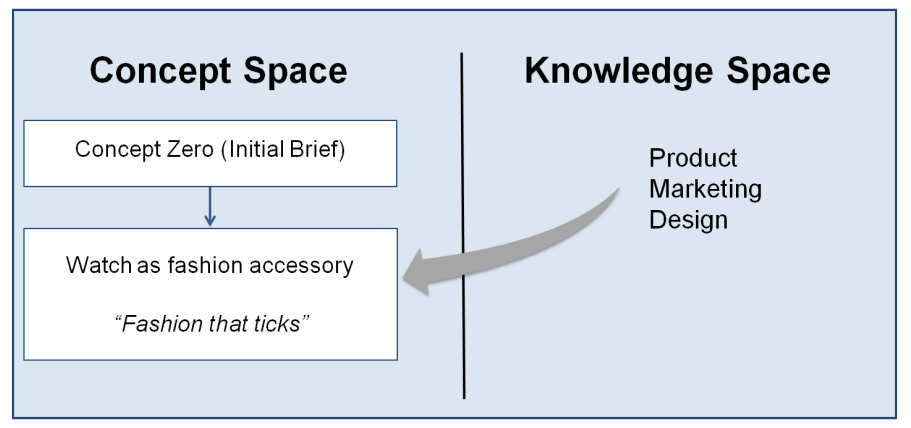

Figure 4. Interactions between concept and knowledge spaces in the later stages of the Swatch design

\section{Conclusions and Lessons Learned}

An essential condition in this design process was to fundamentally question "everything that goes into a watch", an idea that had been taken for granted before, while preserving its traditional properties so the customer could still recognize them. The Swatch is finally an oxymoron: a watch with a case, glass, hands, strap, etc. that is no longer a watch in that it has new properties as a fashion accessory. From our analysis of this case, we conclude by offering two key lessons: i) a reuse strategy for design and ii) the importance of concept and knowledge as cornerstones of the design process.

\section{Reuse what already exists}

Reusing old ideas has been part of innovation strategies for a long time (Majchrzak et al., 2004). But, using what already exists and hiding it from the customer while only showing them some new aspect instead, is a difficult thing to do. In the case of Swatch, many aspects of existing watchmaking knowledge went into its design: the case mainplate had already been patented in 1880; cheap plastic watches had already been launched by Fortis, Oris, and other brands; the handsetting mechanism was inspired by the one on Cyma clocks from the 1930s; a simplified Lavet motor had been developed by Ebauches Bettlach; and so on. Reusing existing ideas supposes a huge knowledge base. Mock and Müller were not just aware of modern or new technologies, they also acted as genealogists and historians of watchmaking techniques. Some recycled knowledge also came from elsewhere, including sectors entirely unrelated to watchmaking. For example, welding the Plexiglas watch glass to the case in ABS plastic comes from a common practice in manufacturing car headlights. It is sometimes necessary to look in distant sectors for the knowledge needed for the design process. We never disrupt from scratch!

\section{Concept and knowledge are the cornerstones of the design process}

The Swatch case demonstrates that, without knowledge, we cannot design; but, with only knowledge, we can only reproduce. Innovation requires knowledge and creativity. The Swatch design process adhered to the concept-knowledge) theory of design. There was rigorous and continuous interaction between concepts and knowledge with engineers participating in conceptual issues and creative people involved with engineering matters. The engineers are also on the concept side and the creative people on the knowledge side of engineering. No space is off limits for innovation, including those areas occupied for long periods by leading players and proven solutions.

\section{Recommended Reading}

La fabrique de l'innovation by Gilles Garel and Elmar Mock (2012). English translation scheduled for publication in 2016 by Taylor and Francis. 


\section{Lessons in Creativity from the Innovative Design of the Swatch}

\section{Gilles Garel}

\section{About the Author}

Gilles Garel is a Full Chair Professor of Innovation Management at the Conservatoire National des Arts et Métiers (CNAM) in Paris, France. He is also Professor at l'École Polytechnique in Palaiseau, France. At the Laboratoire Interdisciplinaire de Recherche en Sciences de l'Action (LIRSA) at CNAM Paris, Gilles conducts research in the field of innovation and design management in close collaboration with innovative firms and organizations.

Citation: Garel, G. 2015. Lessons in Creativity from the Innovative Design of the Swatch. Technology

(cc) BY

Innovation Management Review, 5(7): 34-40.

http://timreview.ca/article/912

Keywords: innovation, design, Swatch, creativity, engineering, concept, knowledge

\section{References}

Christensen, C. 1997. The Innovator's Dilemma: When New Technologies Cause Great Firms to Fail. Cambridge, MA: Harvard Business School Press.

Donzé, P. Y. 2009. Histoire de l'industrie horlogère suisse. De Jacques David à Nicolas Hayek (1850-2000). Neuchâtel, Switzerland: Éditions Alphil.

Gabarro, J. J., \& Zehnder, D. E. D. 1994. Nicolas G. Hayek. Harvard Business School Case 495-005.

Garel, G., \& Mock, E. 2012. La fabrique de l'innovation. Paris: Dunod.

Hatchuel, A., \& Weil, B. 2002. C-K Theory: Notions and Applications of a Unified Design Theory. In Proceedings of the Herbert Simon International Conference on Design Science, Lyon, 15-16 March 2002.

Hatchuel, A. \& Weil, B. 2003. A New Approach of Innovative Design: An Introduction to C-K Design Theory. In Proceedings of ICED'03, the 14th International Conference on Engineering Design, Stockholm, Sweden.

Le Masson, P., Weil, B., \& Hatchuel, A. 2010. Strategic Management of Design and Innovation. Cambridge, UK: Cambridge University Press.

Wegelin, J. 2009. Mister Swatch: Nicolas Hayek und das Geheimnis seines Erfolges. Zürich, Switzerland: Éditions Nagel \& Kimche.

Majchrzak, A., Cooper, L. P., \& Neece, O. E. 2004. Knowledge Reuse for Innovation. Management Science, 50(2): 174-188. http://dx.doi.org/10.1287/mnsc.1030.0116

Moon, Y. 2004. The Birth of Swatch. Harvard Business School Case 504-096.

Trueb, L. F. 2005. The World of Watches: History, Technology, Industry. New York: Ebner Publishing International.

Tushman, M. L., \& Radov, D. 2000. Rebirth of the Swiss Watch Industry, 1980-1992 (A). Harvard Business School Case 400-087. 